\title{
Fairness Norms and the Incidence of Environmental Subsidy
}

\author{
Toshihiro Uchida \\ School of Economics, Chukyo University, Nagoya, Japan \\ Email: t-uchida@mecl.chukyo-u.ac.jp
}

Received August 18, 2012; revised September 20, 2012; accepted September 30, 2012

\begin{abstract}
Although fairness concerns are frequently discussed in the real world environmental politics, their effects are relatively neglected in the environmental economics literature. Using a survey method, this paper attempts to reveal how fairness norms affect the incidence of subsidy both in the short-run and long-run. The results indicate that statutory incidence (legal right to receive subsidy) affects people's fairness norms on who should receive subsidy. In particular it is considered unfair for a firm to receive a part of the subsidy when it is legally granted to the consumer side. If firms avoid behaviors that are considered unfair, the tax and subsidy equivalence theorem may not hold under this situation. The survey results also reveal that fairness norms affect the incidence of subsidy in the long-run, in a sense that the allocation of gains that are generated due to subsidy is affected. People find it fair if allocation is made in proportion to firms' own effort. Therefore, if an increase in profit is achieved by activities directly supported by subsidy, people find it less justifiable for firms to keep all the gains by themselves and thus firms may be forced to share the gains with consumers.
\end{abstract}

Keywords: Environmental Economics; Fairness; Social Norms; Subsidy; Tax Equivalence Theorem

\section{Introduction}

The debate over environmental policies often generates controversies. Protecting the environment tends to involve trade-offs between the economy and the environment at least in the short run. Consequently, heated debate often arises over designing how to distribute the costs and benefits of a policy among potentially affected entities [1]. For example, introduction of environmental taxes typically faces strong opposition from the industries that are likely to bear heavier burdens. Feed-in-tariffs, which attempt to boost renewable energy by providing financial incentives to renewable electricity producers, are also causing distributive concern [2,3]. Since feed-in-tariffs charge higher energy bills to electricity users to finance the program, the financial burden on a typical household can become increasingly heavy as renewable electricity becomes more prevalent and the total payments to electricity producers increase.

Although fairness concerns are frequently discussed in the real world environmental politics, the issues are relatively neglected in the environmental economics literature [1]. Of particular interest of this paper is the effect of fairness norms on the tax and subsidy equivalence theorem. The theorem states that the final distribution of the burden of a tax (economic incidence) does not depend on who actually pays the tax (statutory incidence). Or in the context of subsidy, the final distribution of the benefit of a subsidy does not depend on who actually receives the subsidy [4]. The tax and subsidy equivalence theorem is considered one of the basic established theories in microeconomics. However, its empirical validity has been recently challenged. For example, Kerschbamer and Kirchsteiger [5] demonstrated using laboratory experiments that the equivalence theorem does not hold due to a shift in behaviorally relevant social norms. The distribution of subsidy is influenced by behaviors of firms in the market. If firms avoid the behaviors that are deemed unfair, the incidence of subsidy may be affected by fairness norms.

In this paper, we attempt to reveal people's fairness norms on the pricing behaviors of firms in the presence of subsidy and investigate how fairness norms can affect the incidence of subsidy both in the short-run and longrun. By analyzing these issues, this paper attempts to add new empirical evidence to the literature on the role of fairness in environmental economics. Specific attention is given to the following two aspects: 1) How statutory incidence (legal right to receive subsidy) affects fairness norms and the incidence of subsidy; and 2) How fairness norms affect the allocation of gains from subsidy in the long-run. We also discuss a possibility that the tax and subsidy equivalence theorem may not always hold.

This paper is structured as follows. The next section 
provides brief review of the relevant literature. Section 3 explains the survey method. Section 4 presents results, and Section 5 concludes the paper.

\section{Literature Review}

An increasing number of evidence suggests that fairness norms play important roles in shaping economic outcomes. A fairness norm refers to "a standard of conduct that most people hold about what is fair and not fair" [6]. These views form the ethical behavioral principles of economic agents, which may influence their decision making processes. The evidence on the effect of fairness norms on individual decision making has been accumulated in the experimental economics literature.

In the dictator game, a proposer decides to share a certain amount of money with a responder. The responder receives whatever amount the proposer decides to give him, and the proposer obtains the remaining portion. Although standard economic theory suggests that a self-interested proposer gives nothing to the responder, typically more than half the proposers give something, and some even offer a 50:50 split which can be considered a fair division of the stake [7]. In the ultimatum game, a responder has an option to either accept or reject the offer made by a proposer; if the offer is rejected, both players receive nothing. Thus, money-maximizing individuals should accept any offer however small it is, and backward induction suggests that proposers should offer minimal amount. In reality, however, the majority of proposers offer $40 \%-50 \%$ of the stake, and responders tend to reject low offers, punishing what they consider unfair offers by giving up their own profit [8]. Similar punishment behaviors are observed in the public goods game. In the public goods game, players decide if and how much they contribute to a public good. When players are given an opportunity to punish others, free riders (who do not contribute to the public good) are severely punished even if punishment is costly to the punisher. This in turn increases contribution rate to avoid punishment from other players for being a free rider [9]. These observations imply that some people are willing to give up their own payoff in order to punish other people's behaviors that are against fairness norms, and that avoiding punishment partially motivates individuals to behave consistently with fairness norms.

In the context of decision-making of firms, Kahneman et al. [10] investigated how fairness norms could constrain profit-seeking behaviors of firms. They conducted a survey with a series of hypothetical scenarios and asked respondents whether they think the pricing behavior of the firm described in each scenario is fair or not. Through these questions, they elicited the fairness norms that people hold toward pricing and wage setting behaviors of firms. Their findings are summarized in the dual entitle- ment theory: the prices or profits at the currently prevailing transactions (reference prices or reference profits) form the benchmark against which people judge fairness. People consider that buyers have an entitlement to the reference prices and firms have an entitlement to the reference profits. The act of increasing profit by increasing price from the reference price is generally considered unfair, and it is considered acceptable only when the firm's reference profit is threatened. Kahneman et al. [10] then attempted to explain market anomalies such as sluggish and incomplete market adjustments by the dual entitlement theory. They argued that if firms ignore the entitlement of buyers, the act would cause anger among buyers and may reduce the demand for the firm's product in the long-run. Therefore, even if there are profit-seeking opportunities in the short-run, firms may forgo the opportunities for the sake of protecting the long-run profit. This in turn leads to seemingly anomalous market behaviors of firms. For example, even in the presence of excess demand, firms may not increase price because doing so would ignore the buyers' entitlement at the current price. In this sense, profit-seeking behaviors of firms are constrained by fairness norms and the behaviors of firms may diverge from what the standard economic theory predicts.

The role of fairness in the tax and subsidy equivalence theorem is discussed in Kerschbamer and Kirchsteiger [5]. In their modified ultimatum game, a tax is levied either on the proposer or the responder. If a tax is levied, a certain fixed amount (a tax) is subtracted from the gross payment that the player was supposed to receive in the absence of tax. The experimental results show that contrary to what the equivalence theorem predicts, the net payoff a player receives changes depending on who actually pays the tax. The side of the player to whom the tax is levied bears a significantly larger share of the burden [5]. They argue that the changes in legal obligation to pay a tax also change social norms regarding who should bear the tax burden, though they did not show sufficient evidence to back up this claim.

The above studies combined imply that decisionmaking processes of both individuals and firms are affected by fairness norms. Avoiding punishment partially motivates individuals and firms to behave consistently with fairness norms. For example, if firms violate the entitlement of buyers, their long-run profits may decline through reduced demand for their products and services. Due to the influence of social norms including fairness norms, the behaviors of economic agents may diverge from what the standard theory predicts including the tax and subsidy equivalence theorem.

\section{Methods}

The basic research method employed in this study is 
similar to Kahneman et al. [10]. We conducted a survey with a series of hypothetical scenarios and asked respondents whether they think the situation described in each scenario is fair or not. The respondents consisted of a random sample of 744 residents in Japan between the age of 20 and 69. We designed a web-based survey and it was executed in February 2012 by goo Research, one of the major market research companies in Japan. ${ }^{1}$ To reduce the burden of respondents, we divided questions into two versions $\mathrm{A}$ and $\mathrm{B}$, such that respondents were assigned to either of them. Version A had 370 respondents and version B had 374 respondents, which gave a total of 744 samples. $^{2}$

The survey specifically assumed a hypothetical company $\mathrm{C}$, which produces next-generation solar power systems. At the beginning of the questionnaire, background information on Company $\mathrm{C}$ and its products was explained as follows: ${ }^{3}$

The following questions are based on hypothetical activities of a company (Company C). Company C produces next-generation solar power systems for household use and sells them directly to its consumers. With the use of Company C's next-generation solar power systems, consumers can reduce electricity consumption and air pollutant emission associated with the electricity consumption. With the purchase of each unit, a household is expected to make an average contribution to the environment equivalent to JPY 100,000 in monetary terms throughout the system's service life. Moreover, if the system's efficiency increases with research and development (R\&D), the environmental contribution associated with the use of the system is expected to surpass JPY 100,000.

Then, the ensuing questions presented various hypothetical pricing behaviors of Company $\mathrm{C}$ in the presence of subsidy. The distribution of subsidy is influenced by what kind of pricing behaviors firms take in the market. If firms avoid the behaviors that are deemed unfair, this may affect the incidence of subsidy. In this sense, fairness norms can affect the incidence of subsidy. In each question, we asked respondents to indicate how strongly they agree that Company C's course of action is fair. Through these questions, we infer people's fairness norms on the pricing behaviors of firms in the presence

\footnotetext{
${ }^{1}$ The use of web-based survey is rapidly increasing in the environmental economics literature. It has been shown that appropriately designed web-based surveys can produce reliable results similar to the conventionally used methods such as mail surveys and telephone surveys $[11,12]$.

${ }^{2}$ Each version contains 8 questions. The ensuing discussions take only a part of the questions that are relevant for this study's research questions.

${ }^{3}$ The questionnaire was originally written in Japanese. For the purpose of presentation, a translated version is presented throughout this paper.
}

of subsidy and attempt to reveal how fairness norms can affect the incidence of subsidy. We specifically investigate the following two research questions:

1) How statutory incidence (legal right to receive subsidy) affects fairness norms and the incidence of subsidy.

Kerschbamer and Kirchsteiger [5] argue that the changes in legal obligation to pay a tax also change social norms regarding who should bear the tax burden. Their experimental results show that the side of the player to whom the tax is levied bears a significantly larger share of the burden. We investigate whether similar results hold for the case of subsidy. That is, we examine whether people think it is fair when the side of the agent to whom the subsidy is provided receives a larger share of it.

2) How fairness norms affect the allocation of gains from subsidy in the long-run.

If subsidy is introduced to encourage environmental businesses or environmentally-friendly products (e.g., the next-generation solar power systems in our hypothetical scenario), it is likely to produce gains (benefits) in the long-run from activities related to subsidy. For example, profits of the firms may increase or a part of the increased profits may be returned to consumers through reduced market price. How should the gains be shared between firms and consumers in the market? We investigate people's fairness norms on the allocation of gains from subsidy in the long-run.

In each question, respondents were asked to choose one of four answers to express how strongly they agree that Company C's course of action is fair. The answers took the form of ordinal qualitative data, but for the purpose of statistical analyses they were assigned numbers as follows: Strongly agree $=1$, Somewhat agree $=2$, Somewhat disagree $=3$, and Strongly disagree $=4$.

The survey is structured such that the scenario in each question is slightly different from others. This allows us to compare and contrast the effect of a certain specific factor in forming people's fairness norms.

\section{Results}

This section presents the survey results. By comparing how people's fairness perceptions change under different scenarios, we attempt to answer the two research questions explained in the previous section.

\subsection{How Statutory Incidence (Legal Right to Receive Subsidy) Affects Fairness Norms and the Incidence of Subsidy}

To investigate this issue, we constructed pairs of scenarios, where Company $\mathrm{C}$ is entitled to the subsidy in one scenario and consumers are entitled in the other scenario. A pair-wise comparison allows us to highlight the effect of statutory incidence on fairness norms. In the following 
questions, the subsidy is assumed to be directed to the research and development expenses of Company $\mathrm{C}$ and therefore consumers do not receive subsidy. The effect of statutory incidence is investigated under these scenarios.

Question 1. ${ }^{4}$ Company C produces next-generation solar power systems for household use and sells them directly to its consumers. In the past year, each unit has been sold for JPY 1 million (approximately 12,500 US Dollars), which is barely over the breakeven price. To promote the growth of environmental Indus- tries, the government decided to introduce a new subsidy for the production of next-generation solar power systems and Company $\mathrm{C}$ now receives a subsidy of JPY 100,000 for the production of each unit. Therefore, after receiving government subsidy, the Company's break-even sales price becomes JPY 900,000 . Company C has decided to continue selling the systems for JPY 1 million per unit-even after receiving the subsidy - to fund research and development required for increasing the efficiency of its solar power systems.

Do you agree that Company C's course of action underlined above is fair (justifiable behavior)? Please choose one of the following responses.

1) Strongly agree $(12.8 \%)$

2) Somewhat agree $(48.9 \%)$

3) Somewhat disagree (29.4\%)

4) Strongly disagree (8.8\%)

The percentage of responses is indicated inside the parentheses after each option. When Company $\mathrm{C}$ is entitled to the subsidy, more than half of the respondents (Strongly agree $(12.8 \%)+$ Somewhat agree $(48.9 \%)=$ $61.7 \%$ ) think it is fair that consumers continue to pay the same price even after the introduction of the subsidy. This fairness perception changes when consumers are legally entitled to the subsidy.

Question 2. ... (same as Question 1) To promote the growth of environmental industries, the government decided to introduce a new subsidy for the purchase of next-generation solar power systems and consumers now receive a subsidy of JPY 100,000 for each unit they purchase from Company C. Therefore, if each unit is sold for JPY 1 million after introduction of the subsidy, Company C's profitability remains constant and consumers can effectively purchase a unit at JPY 900,000, which is JPY 100,000 cheaper than before. Company $\mathrm{C}$ has decided to increase the price by JPY 100,000 and sell each unit at JPY 1.1 million after the subsidy program is implemented, in order to fund research and development

${ }^{4}$ Numbering of the questions is different from the original one in the survey. required for increasing the efficiency of its solar power systems. (This means consumers will effectively pay JPY 1 million, which is the same price as before the introduction of the subsidy).

Do you agree that Company C's course of action underlined above is fair (justifiable behavior)? Please choose one of the following responses.

1) Strongly agree (3.2\%)

2) Somewhat agree (26.2\%)

3) Somewhat disagree $(47.6 \%)$

4) Strongly disagree (23.0\%)

When consumers are entitled to the subsidy, only $29.4 \%$ of the respondents (Strongly agree (3.2\%) + Somewhat agree $(26.2 \%)=29.4 \%)$ think it is fair. The difference in the means of the answers to Questions 1 and 2 are statistically significant. Both the t-test and the Mann-Whitney U nonparametric test reject the null hypothesis that the mean is equivalent with p-values less than 0.01 . Under both scenarios, consumers pay the same price to purchase a unit and Company $\mathrm{C}$ spends the same amount of money on research and development activity. However, the behavior of Company C in Question 2 is judged to be unfair. A natural explanation for this observation seems to be a change in the social norm. Assigning legal right of subsidy to a different party changes the social norm regarding who should receive the subsidy. If people think the party to which legal right is granted should receive the subsidy, people consider it unfair if the subsidy is "taken away" by firms when consumers have the legal entitlement. In essence, this interpretation is consistent with Kerschbamer and Kirchsteiger [5], who proposed the role of social norms to explain the failure of the tax equivalence theorem.

The above interpretation assumes that Company C's behavior is judged to be unfair because of the fact that it ignores consumers' entitlement to the subsidy, not because of the price increase by itself. To ensure this assumption is correct, we compare the result of Question 2 with those of the following questions.

Question 3. Company C produces next-generation solar power systems for household use and sells them directly to its consumers. In the past year, each unit has been sold for JPY 1 million, which is barely over the break-even price. Now due to an increase in material prices, the production costs have increased, thus raising the break-even price to JPY 1.1 million. Company $C$ has decided to increase the price by JPY 100,000 and sell each unit at JPY 1.1 million.

Do you agree that Company C's course of action underlined above is fair (justifiable behavior)? Please choose one of the following responses.

1) Strongly agree (14.3\%) 
2) Somewhat agree (51.9\%)

3) Somewhat disagree (28.9\%)

4) Strongly disagree (4.9\%)

A total of $66.2 \%$ of respondents consider that increasing the price to avoid incurring a loss is fair. Furthermore, as shown in the following question, increasing the price even for the purpose of protecting the existing profit is considered fair.

Question 4. ... (same as Question 3) In the past year, each unit has been sold for JPY 1 million, and Company $\mathrm{C}$ has been making a profit of JPY 100,000 at this sales price. Now due to an increase in material prices, the production costs have increased, which makes it impossible to maintain the JPY 100,000 profit unless sales price becomes JPY 1.1 million. Company $C$ has decided to increase the price by JPY 100,000 and sell each unit at JPY 1.1 million.

Do you agree that Company C's course of action underlined above is fair (justifiable behavior)? Please choose one of the following responses.

1) Strongly agree $(11.2 \%)$

2) Somewhat agree $(48.4 \%)$

3) Somewhat disagree (33.4\%)

4) Strongly disagree (7.0\%)

Now $59.6 \%$ of respondents think Company C's behavior is fair, which is much greater than the percentage of respondents who considered fair in Question 2 (29.4\%). From these answers, it seems reasonable to conclude that simply increasing sales price by itself is not judged to be an unfair behavior even for the purpose of protecting the existing profit. It is the act of ignoring the consumers' entitlement to the subsidy that is considered unfair.

As discussed in Kahneman et al. [10], if firms take actions that are considered unfair, this would cause anger among buyers and may reduce long-run profits of firms. In this sense, fairness norms constrain profit seeking pricing behaviors of firms and affect the incidence of subsidy depending on which side the subsidy is introduced. Several reasons have been proposed for why the tax equivalence theorem may fail under certain conditions. Chetty et al. [13] concluded from field experiment evidence that consumers underreact to less visible taxes due to bounded rationality, leading to divergence from the behaviors predicted by the standard theory. Busse et al. [14] analyzed the incidence of cash incentive promotions in the automobile market. They found that asymmetric information causes customers to obtain a much higher proportion of the incentive if a rebate program is introduced to a customer side rather than a dealer side.

This paper proposes another possible source of the failure of the tax and subsidy equivalence theorem. The theorem may not hold because statutory incidence affects people's fairness norms on who should receive subsidy, which may constrain pricing behaviors of firms and make the behaviors divergent from the standard theory. In essence, this interpretation is consistent with an experimental study by Kerschbamer and Kirchsteiger [5]. We do not contend, however, that the equivalence theorem will always fail. Ruffle [4] contends that non-market forces such as bargaining powers work only in small markets, and the tax equivalence theorem is strongly supported in large markets due to powerful competitive market forces. Therefore, even when strong fairness norms exist, the situations under which the equivalence theorem fails may be limited to small markets.

\subsection{How Fairness Norms Affect the Allocation of Gains from Subsidy in the Long-Run}

Next, we consider a situation in which gains are produced (e.g., profits are increased) in the long-run from activities related to subsidy, and discuss people's fairness norms on how the gains should be allocated between firms and consumers in the market.

Question 5. Company C produces next-generation solar power systems for household use and sells them directly to its consumers. With the aim of promoting the growth of environ- mental industries, government subsidy has been provided since last year for the production of next-generation solar power systems. Company $\mathrm{C}$ has been receiving a subsidy of JPY 100,000 for the production of each unit and utilized the received subsidy to fund research and development aimed at increasing the efficiency of its solar power systems. In the past year, each unit has been sold for JPY 1 million, which is barely over the break-even price. Now, thanks to the research and development supported by the subsidy, the efficiency of the systems has improved. This has increased sales, and Company $\mathrm{C}$ now makes a profit of JPY 100,000 per unit if sold at the price of JPY 1 million. Company $\mathrm{C}$ has decided to continue using the subsidy to fund research and development and sell the systems for JPY 1 million per unit.

Do you agree that Company C's course of action underlined above is fair (justifiable behavior)? Please choose one of the following responses.

1) Strongly agree $(12.7 \%)$

2) Somewhat agree (43.8\%)

3) Somewhat disagree (38.1\%)

4) Strongly disagree (5.4\%)

In this scenario, Company C's profit is increased due to the R\&D activities that have been supported by the 
subsidy. Next scenario considers a situation in which gains are produced due to Company C's own efforts that are unrelated to the subsidy.

Question 6. ... (same as Question 5) which is barely over the break-even price. Now, thanks to cost reductions unrelated to the subsidy, it has become possible to make a profit of JPY 100,000 if each unit is sold at JPY 1 million. Company C has decided to continue using the subsidy to fund research and development and sell the systems for JPY 1 million per unit.

Do you agree that Company C's course of action underlined above is fair (justifiable behavior)? Please choose one of the following responses.

1) Strongly agree (21.9\%)

2) Somewhat agree $(51.9 \%)$

3) Somewhat disagree (22.2\%)

4) Strongly disagree (4.0\%)

The percentage of respondents who consider Company C's behavior to be fair is $56.5 \%$ in Question 5 and $73.8 \%$ in Question 6. The difference in the means is statistically significant. Both the t-test and the Mann-Whitney U nonparametric test reject the null hypothesis that the mean is equivalent with $\mathrm{p}$-values less than 0.01 .

To interpret this result, a study by Konow [15] may be of relevance. Konow [15] investigated people's fairness norms toward allocation of output. The study concludes that one of the conditions for fairness is that allocation is made in proportion to adjusted input, which is basically equivalent to one's own effort level. Although what we deal with here is gains, the fairness norms may be based on a principle similar to the case of output. In the case of Question 6, Company C increases its profit by efforts not related to the subsidy. In the case of Question 5, research and development itself can be considered its own effort but the activity is financially supported by the subsidy. In this sense, not all increase in profit can be attributed to own effort, thus making some people doubt the fairness of Company C's behavior. These observations imply that fairness norms may also affect the incidence of subsidy in the long-run, in a sense that the decision of firms involving the allocation of gains from subsidy may be affected.

\section{Conclusions}

This paper attempted to reveal how fairness norms affect the incidence of subsidy both in the short-run and longrun. In particular, we investigated 1) How statutory incidence affects fairness norms and the incidence of subsidy; and 2) How fairness norms affect the allocation of gains from subsidy in the long-run. Although fairness concerns are frequently discussed in the real world environmental politics, the issues are relatively neglected in the environmental economics literature [1]. This paper tried to add new empirical evidence to this literature.

The survey results indicate that even when consumers pay the same price for a product, people's fairness norms change depending on which side the subsidy is introduced. If statutory incidence affects people's fairness norms on who should receive subsidy, the tax and subsidy equivalence theorem may not hold. This happens because it is considered unfair for a firm to receive a part of the subsidy when it is legally granted to the consumer side and thus firms have incentives to avoid behaviors that are considered unfair in order to protect the long-run profit. We add a caveat, however, that the failure of the equivalence theorem is only likely to happen in small markets in which competitive forces are weak.

The results indicate that fairness norms also affect the incidence of subsidy in the long-run, in a sense that allocation of gains from subsidy is affected. People find it fair if allocation is made in proportion to adjusted input. Therefore, if an increase in profit is achieved by activities directly supported by subsidy, people find it less justifiable when firms keep all the gains by themselves.

There are certainly limitations to this study. The survey questions dealt with specific situations and therefore the results and their interpretations may not be robust. Investigating other situations can check the robustness of the findings of this study. Applying new methods such as field experiment seems a promising direction of future research. Levitt and List [16] argue that experimental results obtained in laboratory settings may not always hold for more naturally occurring settings, and that field experiments can complement experimental studies. Similarly, the results obtained in our hypothetical scenarios may be complemented by field experiments to produce more robust results and possibly new insights. Future research can extend the current study in this direction.

\section{Acknowledgements}

The author acknowledges financial support from KAKENHI (22730203) (Grant-in-Aid for Scientific Research by the Japanese government).

\section{REFERENCES}

[1] O. Johansson-Stenman and J. Konow, "Fair Air: Distributive Justice and Environmental Economics," Environmental and Resource Economics, Vol. 46, No. 2, 2010, pp. 147-166. doi:10.1007/s10640-010-9356-7

[2] T. Nelson, P. Simshauser and S. Kelley, “Australian Residential Solar Feed-In Tariffs: Industry Stimulus or Regressive Form of Taxation?” Economic Analysis \& Policy, Vol. 41, No. 2, 2011, pp. 113-129.

[3] U. Wang, “Germany’s Solar Identity Crisis,” 2012. 
http://www.renewableenergyworld.com/rea/news/article/2 012/01/germanys-solar-identity-crisis

[4] B. Ruffle, "Tax and Subsidy Incidence Equivalence Theories: Experimental Evidence from Competitive Markets,” Journal of Public Economics, Vol. 89, No. 8, 2005, pp. 1519-1542. doi:10.1016/j.jpubeco.2004.04.009

[5] R. Kerschbamer and G. Kirchsteiger, "Theoretically Robust but Empirically Invalid? An Experimental Investigation into Tax Equivalence," Economic Theory, Vol. 16, No. 3, 2000, pp. 719-734.

[6] B. Siers, "An Introduction to Organizational Fairness," 2004.

http://www.chsbs.cmich.edu/leader_model/Development/ media/Targeted\%20Lessons/organizational_fairness.htm

[7] C. F. Camerer, "Behavioral Game Theory: Experiments in Strategic Interaction,” Princeton University Press, Princeton, 2003.

[8] M. A. Nowak, K. M. Page and K. Sigmund, "Fairness versus Reason in the Ultimatum Game," Science, Vol. 289, No. 5485, 2000, pp. 1773-1775. doi:10.1126/science.289.5485.1773

[9] E. Fehr and S. Gachter, "Cooperation and Punishment in Public Goods Experiments,” American Economic Review, Vol. 90, No. 4, 2000, pp. 980-994. doi:10.1257/aer.90.4.980

[10] D. Kahneman, J. L. Knetsch and R. Thaler, "Fairness as a Constraint on Profit Seeking: Entitlements in the Mar- ket,” American Economic Review, Vol. 76, No. 4, 1986, pp. 728-741.

[11] C. M. Fleming and M. Bowden, "Web-Based Surveys as an Alternative to Traditional Mail Methods," Journal of Environmental Management, Vol. 90, No. 1, 2009, pp. 284-292. doi:10.1016/j.jenvman.2007.09.011

[12] S. B. Olsen, "Choosing between Internet and Mail Survey Modes for Choice Experiment Surveys Considering NonMarket Goods," Environmental and Resource Economics, Vol. 44, No. 4, 2009, pp. 591-610. doi:10.1007/s10640-009-9303-7

[13] R. Chetty, A. Looney and K. Kroft, "Salience and Taxation: Theory and Evidence,” American Economic Review, Vol. 99, No. 4, 2009, pp. 1145-1177. doi:10.1257/aer.99.4.1145

[14] M. Busse, J. Silva-Risso and F. Zettelmeyer, "\$1000 Cash Back: The Pass-Through of Auto Manufacturer Promotions," American Economic Review, Vol. 96, No. 4, 2006, pp. 1253-1270. doi:10.1257/aer.96.4.1253

[15] J. Konow, "A Positive Theory of Economic Fairnesss," Journal of Economic Behavior and Organization, Vol. 31, No. 1, 1996, pp. 13-35. doi:10.1016/S0167-2681(96)00862-1

[16] S. Levitt and J. List, "What Do Laboratory Experiments Measuring Social Preferences Reveal about the Real World?” Journal of Economic Perspectives, Vol. 21, No. 2, 2007, pp. 153-174. doi:10.1257/jep.21.2.153 